\title{
BDNF Val66Met modifies the risk of childhood trauma on obsessive- compulsive disorder
}

Sian Megan Joanna Hemmings, Christine Lochner, Lize van der Merwe, Danielle C. Cath, Soraya Seedat and Dan J. Stein

\begin{abstract}
:
Childhood trauma has been linked to the development of later psychopathology, including obsessive-compulsive disorder (OCD). Although evidence exists to suggest that genetic and environmental factors are involved in the aetiology of OCD, little attention has been paid to the interactions that exist between genes and environment. The aim of this study was to investigate gene-byenvironment interactions between childhood trauma and the BDNF Val66Met variant in patients with OCD.
\end{abstract}

Childhood trauma was assessed in 134 OCD patients and 188 controls using the Childhood Trauma Questionnaire (CTQ). Linear regression models were used for statistical analyses. Geneeenvironment interactions were estimated by including a combined genotype and CTQ score in the models as interaction terms. All analyses were adjusted for age, gender, CTQ minimisation-denial score and home language by including them in the logistic regression models as covariates.

Childhood trauma, specifically emotional abuse and neglect, increased the odds of having OCD significantly $(p<0.001)$. Although no significant association was observed between BDNF Val66Met and the development of OCD, interaction analysis indicated that the $B D N F$ Met-allele interacted with childhood emotional abuse to increase the risk of OCD significantly in a dose-dependent manner $(p<$ o.024). To our knowledge, this is one of the first studies to investigate geneeenvironment interactions in OCD, and the findings indicate the importance of collating genetic and environmental variables in future studies.

\section{Introduction}

Obsessive-compulsive disorder (OCD) is a chronic and disabling psychiatric disorder with a lifetime prevalence of approximately 2\% (Angst et al., 2004; Ruscio et al., 2010). A number of twin (van Grootheest et al., 2005) and family (Black et al., 1992; Do RosarioCampos et al., 2005; Hanna et al., 2005; van Grootheest et al., 2005; Nicolini et al., 
2009; Pauls, 2010) studies indicate that genetic factors contribute to its aetiology. The environment has also been found to play a role in the development of the disorder e twin studies indicate that approximately $50 \%$ of individual variation in OCD is due to nongenetic, environmental factors (Samuels, 2009).

A number of environmental risk factors have been identified for OCD, including stressful and traumatic life events (McKeon et al.,1984; Gothelf et al., 2004). However, childhood trauma and its association with the development of OCD has, to date, not been widely studied. Mathews et al. (2008) investigated the association between childhood trauma and obsessive-compulsive (OC) symptoms in a community sample and found that, although emotional abuse and physical neglect were associated with the occurrence of OC symptoms, this was dependent on the co-occurrence of anxiety symptoms. However, the authors did observe a direct association between emotional abuse and high levels of OC symptoms ('probable' OCD). Briggs and Price (2009) observed an association between adverse childhood experience and OC symptoms, but only in the presence of anxiety and depression. In one of the few studies to investigate the association between childhood trauma and clinical OCD thus far, Lochner et al. (2002) observed a significant association between childhood emotional neglect and OCD in females. However, not all individuals who experience childhood adversity will necessarily develop psychopathology or OCD specifically; arguably a pre-existing vulnerability is required to interact with the adverse life event(s) to increase risk.

Gene-by-environment ( $\mathrm{G} \times \mathrm{E}$ ) interaction analyses investigate the role that environmental factors play in the development of a disorder, and how genetic constitution possibly modifies this association. A number of studies have indicated that brain-derived neurotrophic factor (BDNF) plays a role in modulating the outcome of childhood trauma in terms of psychopathology (Perroud et al., 2008; Aguilera et al., 2009; Gatt et al., 2009; Pregelj et al., 2011). BDNF is a key neurotrophin that is widely expressed in the mammalian brain, where it plays a crucial role in neurodevelopment, morphology and differentiation, and synaptic plasticity (Hoglinger et al., 1998; Huang and Reichardt, 2001; Lu, 2003; Duman and Monteggia, 2006). BDNF has also been hypothesised to play a role in the development of OCD (Stein et al., 2008). The gene encoding BDNF contains a single nucleotide polymorphism (SNP) resulting in a valine-to-methionine substitution at amino acid 66 (Val66Met, rs6265) in the $5^{\mathrm{O}}$ pro-BDNF domain. The Met-allele has been found to affect the intracellular trafficking of the pro-BDNF polypeptide, thereby inhibiting the secretion of BDNF from activated neurons (Egan et al., 2003). BDNF Val66Met has been widely investigated in $\mathrm{OCD}$, but the results have been largely inconsistent. Hall et al. (2003) observed an association between the Val-allele and childhood-onset OCD, although this result was not replicated in a later study (Mossner et al., 2005). Our group observed an association between the Met-allele and OCD in male patients with early-onset OCD (Hemmings et al., 2008). However, in the same study, the Val/Val genotype was found to be associated with increased severity of OCD in females. In an extension of our study, Katerberg et al. (2009) observed an association between female Met-allele carriers and less severe 
OCD. However, Dickel et al. (2007), Wendland et al. (2007), Alonso et al. (2008) and Tukel et al. (2012) found no association between BDNF Val66Met and OCD.

Numerous studies have implicated BDNF Val66Met in moderating the effect of stressful life events and the subsequent risk for psychopathology. For example, it has been shown that Metallele carriers are more vulnerable to stress (Casey et al., 2009) and to the development of depression (Carver et al., 2011), after experiencing early life adversity. To our knowledge, there are no studies investigating whether BDNF Val66Met moderates the effect of stressful life events and risk for OCD. The aim of the present study was thus to investigate the role that the BDNF Val66Met variant may play in moderating the causal effect of early life stress on the susceptibility to OCD.

\section{Methods}

2.1. Recruitment, clinical assessment and self-report measures

Unrelated South African Caucasian individuals with a primary diagnosis of OCD $(n=134)$ were recruited through physician referral, media advertisements, the Mental Health Information Centre of Southern Africa (MHIC) and the OCD Association of South Africa (OCDSA). Controls ( $n=188$ ) comprised randomly selected Caucasian blood donors who were given a brief screening test and were self-declared psychologically healthy (i.e. not diagnosed with any psychiatric disorders). For the purposes of this study, South African Caucasians were classified as those participants who were white and had self-reported home languages of English and/or Afrikaans.

Specific demographic data, including age at interview and gender were obtained from all participants. Patients were assessed for a primary diagnosis of DSM-IV OCD using the Structured Clinical Interview for Axis I Disorders e Patient Version (SCID-I/P) (First et al., 1998). The Structured Clinical Interview for Obsessive-Compulsive Spectrum Disorders (SCID-OCSD) (Du Toit et al., 2001) was administered by a trained mental health professional (i.e. a clinical psychologist, psychiatrist or psychiatric nurse) and was used to assess comorbid OCD-related conditions not covered in the SCID-I/P. OCD patients with a significant history of neurological disease, schizophrenia, schizo-affective disorder, other psychotic conditions or a history of substance dependence, as determined from the interviews or previous medical records, were excluded from the study. Patients at baseline (not receiving any form of treatment for OCD) as well as patients on treatment for OCD were included in the study.

The Yale-Brown Obsessive-Compulsive Severity Scale (YBOCS) was used to assess of the severity of obsessive-compulsive symptoms (Goodman et al., 1989). The Childhood Trauma Questionnaire (short form) (CTQ-SF) (Bernstein and Fink, 1998) was used to assess five types of negative childhood experiences, namely physical abuse, physical neglect, emotional abuse, emotional neglect and sexual abuse, in both the OCD and control groups. Each item was rated from 1 (never) to 5 (very often). Total scores ranged from 5 to 25 for each type of trauma. The minimisation/denial scale of the CTQ provides an indication of potential underreporting of childhood maltreatment, and thus false-negatives. The scale 
comprises three items, and scoring was dichotomised ("very often true" $1 / 41$; all other responses $1 / 4 \mathrm{O}$ ) and summed. A total of one or above indicates possible underreporting of maltreatment (Bernstein and Fink, 1998), while the highest score of three represents extreme misrepresentation or denial of childhood maltreatment.

The protocol was approved by the Health Research Ethics Committee at Stellenbosch University, and all participants provided written, informed consent after being presented with a complete description of the study.

\subsection{DNA extraction, amplification and genotyping}

Peripheral blood was drawn from all participants and genomic DNA was subsequently extracted from each blood sample using the standard phenol/chloroform method. The $B D N F$ Val66Met polymorphism (rs6265) was genotyped as previously described (Hemmings et al., 2008).

\subsection{Statistical analyses}

Fisher's exact test was used to compare gender and home language and a $t$-test was used to compare age at assessment between the two diagnostic groups (OCD and control). Only home language differed significantly between the diagnostic groups. However, as all the aforementioned variables are possible confounders, all subsequent analyses were adjusted for age, gender and home language (as a proxy for possible population structure). It is essential to correct for population structure, given that spurious association may result if the genetic background of the sub-populations comprising the sample under investigation differ (Astle and Balding, 2009).

Dichotomous (e.g. susceptibility to OCD and gender) and categorised variables (home language) were summarised as counts and percentages (\%). Dichotomous outcomes (i.e. the dependent variables) were analysed using logistic regression models, to facilitate adjustment for confounders (i.e. the independent variables). Numerical dependent variables (i.e. age at assessment, age at onset of OCD, CTQ scores) were analysed using linear models, to enable adjustment for confounders (i.e. the independent variables), and summarised as medians (interquartile ranges [IQRs]), since some had skewed distributions.

Genetic association with OCD (the diagnosis being a dichotomous dependent variable) was assessed in two ways: by coding genotypes as categories (with 2 degrees of freedom) or minor additive allele counts ( 1 degree of freedom) (where it is assumed that the combined effect of each of the alleles is equal to the sum of the individual effects of each allele). For testing the interaction between CTQ score and a genetic variable on OCD, a statistical additive allelic-by-CTQ interaction term (independent numerical variable) (together with main effects [independent variables]) was included in the models (where 'additive allele' refers to the number of minor alleles). 
A $p<0.05$ was considered significant. The freely available programming environment, $\mathrm{R}$, was used for all statistics. The R package genetics (Warnes et al., 2011) was used to estimate HardyeWeinberg equilibrium probabilities, and genotype and allele frequencies.

\section{Results}

\subsection{Demographic variables}

In total, 134 OCD patients (54 [40\%] male; 80 [60\%] female) and 188 control participants (80 [43\%] male; 108 [57\%] female) were included. Gender distributions were similar in the diagnostic groups $(p=0.731)$. Age at assessment was recorded for 187 (99\%) OCD patients and all the controls, with medians of 34 years (range: 12-71 years) and 34 years (range: 1772 years) for the OCD and control groups, respectively $(p=0.288)$. The home language distribution differed significantly between OCD and control groups $(p<0.001)$. The majority of the sample was Afrikaans-speaking in both the OCD (52\%) and control (65\%) groups, with English-speaking individuals comprising $44 \%$ and $22 \%$ of the OCD and control groups, respectively. The remainder of the sample comprised those who were both English and Afrikaans-speaking. All subsequent analyses were adjusted for gender, age and home language.

\subsection{Clinical variables}

Data pertaining to age at onset of OCD was available for 127 (95\%) (51 [94\%] male, and 76 [95\%] female) patients. The median age at onset of OCD was 13 years (interquartile range $[\mathrm{IQR}]=8.5 \mathrm{e} 22$ years), and the median YBOCS score was $21(\mathrm{IQR}=16 \mathrm{e} 24)$. The most prevalent comorbid disorder was major depressive disorder (MDD), which was diagnosed in $63 \%(84 / 134)$ of the OCD patients. Table 1 provides a summary of the frequency of self-reported childhood trauma in the OCD and control groups for each of the CTQ subscales. Median total and subscale CTQ scores were compared between OCD and control groups, and all models were adjusted for age, gender, language and CTQ minimisation/denial score (Table 2). Because more than half of the OCD patients presented with comorbid MDD, it was necessary to determine whether any significant associations observed could be attributed to the presence of OCD alone, or to the co-occurrence of the two disorders. The $p$-values in the last two columns of Table 2 compare the CTQ scores between: i) OCD and control groups and ii) OCD patients with comorbid MDD and those without MDD.

Emotional neglect was the most common form of childhood trauma in both the OCD and control groups (Table 1). A higher total CTQ score was found to be significantly associated with OCD ( $p=0.005$ ) (Table 2). Specifically, OCD patients were found to possess significantly higher levels of emotional abuse and neglect compared to control participants ( $p<0.001$ for both comparisons). For each unit increase in emotional abuse or neglect CTQ score, the odds ratio of having OCD (versus not having OCD) was 1.14 (95\% CI: 1.07e1.22 and 95\% CI: 1.08e1.23 for a unit increase in emotional abuse and emotional neglect score, respectively). When emotional abuse and emotional neglect scores were compared between those individuals with comorbid MDD and those without, no significant 
differences were observed $(p=0.224$ and $p=0.093$ for emotional abuse and emotional neglect, respectively) (Table 2).

Within the OCD group, male OCD patients were found to report significantly more emotional neglect ( $p=0.01)$, with the median CTQ score for emotional neglect in males being 13 [IQR: 8-17] compared to 9 [IQR: 6-13] for females. Total CTQ score was not associated with age at onset ( $p=0.823)$; however, individuals with increased emotional abuse scores exhibited significantly increased YBOCS severity scores $(p=0.031$; increase in YBOCS $=0.31$ [95\% CI: 0.03-0.59] for a unit increase in emotional abuse score). In addition, physical neglect was found to be nominally associated with comorbid MDD ( $p=0.047$; OR of MDD for a unit increase in physical neglect score $=1.27$ [95\% CI: 1.03-1.67]) (Table 2).

\begin{tabular}{|c|c|c|c|c|c|c|}
\hline \multirow{2}{*}{$\begin{array}{l}\text { Type of } \\
\text { childhood } \\
\text { trauma }\end{array}$} & \multicolumn{3}{|c|}{ Controls ( $n[\%])$} & \multicolumn{3}{|c|}{$\mathrm{OCD}(n[\%])$} \\
\hline & $\begin{array}{l}\text { Females } \\
n=108\end{array}$ & $\begin{array}{l}\text { Males } \\
n=80\end{array}$ & $\begin{array}{l}\text { Total } \\
n=188\end{array}$ & $\begin{array}{l}\text { Females } \\
n=80\end{array}$ & $\begin{array}{l}\text { Males } \\
n=54\end{array}$ & $\begin{array}{l}\text { Total } \\
n=134\end{array}$ \\
\hline $\begin{array}{l}\text { Emotional } \\
\text { abuse }\end{array}$ & $29(26.9)$ & $25(31.3)$ & $54(28.7)$ & $40(50.0)$ & $33(61.1)$ & $73(54.5)$ \\
\hline Physical abuse & $18(16.7)$ & $28(35.0)$ & $46(24.5)$ & $21(26.3)$ & $29(53.7)$ & $50(37.3)$ \\
\hline Sexual abuse & $27(25.0)$ & $8(10.0)$ & 35 (18.6) & $26(32.5)$ & $17(31.5)$ & $43(32.1)$ \\
\hline $\begin{array}{c}\text { Emotional } \\
\text { neglect }\end{array}$ & $27(25.0)$ & $35(43.8)$ & $62(33.0)$ & $36(45.0)$ & $38(70.4)$ & $74(55.2)$ \\
\hline $\begin{array}{l}\text { Physical } \\
\text { neglect }\end{array}$ & $24(22.2)$ & $29(36.3)$ & $53(28.2)$ & $7(8.8)$ & $16(29.6)$ & $23(17.2)$ \\
\hline
\end{tabular}

Table 2

Median and interquartile ranges of scores for each of the CTQ subscales, in control and OCD patients.

\begin{tabular}{|c|c|c|c|c|c|c|}
\hline & Control & OCD & $\mathrm{OCD}+\mathrm{MDD}$ & $\mathrm{OCD}-\mathrm{MDD}$ & $\begin{array}{l}p \text {-Value } \\
\text { OCD vs. control }\end{array}$ & $\begin{array}{l}p \text {-Value } \\
\text { OCD + MDD vs. } \\
\text { OCD - MDD }\end{array}$ \\
\hline$n$ & 188 & 134 & 83 & 51 & & \\
\hline Physical abuse & $6(5-7)$ & $6(5-9)$ & $6(5-8)$ & $6(5-9)$ & 0.284 & 0.114 \\
\hline Sexual abuse & $5(5-5)$ & $5(5-7)$ & $5(5-6)$ & $5(5-7)$ & 0.111 & 0.718 \\
\hline Emotional neglect & $7(5-11)$ & $10(7-15)$ & $10(6-13)$ & $11(7-16)$ & $<0.001$ & 0.093 \\
\hline Physical neglect & $5(5-8)$ & $5(5-7)$ & $5(5-6)$ & $6(5-7)$ & 0.054 & 0.047 \\
\hline
\end{tabular}

The $p$-values in the last two columns of the table compare the mean CTQ scores between i) OCD and control groups and ii) OCD patients with comorbid MDD (OCD + MDD) and those without MDD (OCD - MDD); p-values $<0.05$ are taken to be significant (indicated in bold font).

Table 3

Genotype counts and frequencies (\%) of BDNF Val66Met in OCD and control individuals.

\begin{tabular}{lccccc}
\hline \multirow{2}{*}{ Genotype } & \multicolumn{2}{l}{ Control } & & \multicolumn{2}{l}{ OCD } \\
\cline { 2 - 3 } \cline { 6 - 6 } & Female $n(\%)$ & Male $n(\%)$ & & Female $n(\%)$ & Male $n(\%)$ \\
\hline Met/Met & $3(2.8)$ & $3(3.8)$ & & $2(2.8)$ & $1(2.0)$ \\
Val/Met & $33(30.8)$ & $17(21.2)$ & & $17(23.6)$ & $16(32.7)$ \\
Val/Val & $71(66.4)$ & $60(75.0)$ & & $53(73.6)$ & $32(65.3)$ \\
Met-allele & $39(18.2)$ & $23(14.4)$ & & $21(14.6)$ & $18(18.4)$ \\
\hline
\end{tabular}

Abbreviations: BDNF, brain-derived neurotrophic factor. 


\begin{tabular}{lllll}
\hline $\begin{array}{l}\text { Emotional } \\
\text { abuse }\end{array}$ & $\begin{array}{l}\text { Emotional } \\
\text { neglect }\end{array}$ & $\begin{array}{l}\text { Physical } \\
\text { abuse }\end{array}$ & $\begin{array}{l}\text { Physical } \\
\text { neglect }\end{array}$ & $\begin{array}{l}\text { Sexual } \\
\text { abuse }\end{array}$ \\
\hline $\mathbf{0 . 0 2 4}^{*}$ & 0.076 & 0.771 & 0.562 & 0.525 \\
\hline
\end{tabular}

Asterisk indicates statistically significant interaction, $p<0.05$; all $p$-values were adjusted for age, gender, language and minimisation/denial score; $p$-values $<0.05$ are taken to be significant (indicated in bold font).

\subsection{Genetic variables}

DNA was available for 121 (90\%) OCD patients and 187 (99\%) controls. The BDNF Val66Met SNP was in HardyeWeinberg equilibrium ( $p=0.601$ in the control group). Table 3 indicates the genotype counts and percentages for BDNF Val66Met in the OCD and control groups.

No statistically significant associations were observed when genotype and allele distributions of BDNF Val66Met were compared between the OCD and control groups ( $p=0.987$ [genotype], $p=0.914$ [allele]) (Table 3).

\section{4. $G \times E$ interactions}

The $p$-values for the interaction between BDNF Val66Met and reported childhood trauma on OCD susceptibility are provided in Table 4. All values are adjusted for age, gender, language and CTQ minimisation/denial score.

A box plot indicating the distribution of CTQ scores per BDNF Val66Met genotype, in OCD patients and controls is indicated in Fig. 1. BDNF Val66Met was found to interact with emotional abuse on the risk of OCD, in a dose-dependent manner. The predicted increase in the odds of having OCD, for one unit increase in emotional abuse CTQ score, is $35 \%$ for heterozygous individuals and $61 \%$ for individuals homozygous for the Met-allele. This significant interaction is illustrated in Fig. 2.

Box plots representing the distribution of age at onset and YBOCS score per BDNF Val66Met genotype are provided in Figs. 3 and 4, respectively. No significant associations were observed between BDNF Val66Met and age at onset ( $p=0.711$ ) or YBOCS score ( $p=$ 0.832). When the effect of the interaction between BDNF Val66Met and CTQ score on age at onset of OCD was investigated, we observed no significant association ( $p=0.316$ for total CTQ score). Likewise, no significant association was observed when the interaction between BDNF Val66Met and CTQ score on YBOCS severity score was analysed ( $p=0.900$ for total CTQ score).

\section{Discussion}

To our knowledge, this study is the first to investigate the interaction between childhood trauma and OCD, and the manner in which this relationship is modified by BDNF Val66Met. To this end, OCD patients reported significantly more childhood trauma in the form of emotional neglect and emotional abuse compared to controls. These results are in line with previous findings from our group, where childhood 
emotional neglect was found to be significantly increased in female OCD patients compared to controls (Lochner et al., 2002). The present study utilised a subset of the patients and controls investigated in the earlier study; however, the sample size in the present study was significantly larger, and included male OCD and control participants, complementing and expanding on the previous study.

The estimated risk of OCD in individuals who had experienced childhood emotional abuse was associated with the BDNF Met-allele in a dose-dependent manner, with individuals homozygous for the BDNF Met-allele (carrying two Met-alleles) possessing almost double the risk of having OCD compared to Val66Met heterozygotes (carrying only one Met-allele). The BDNF Val66Met polymorphism is functional, with the Met-allele resulting in reduced activity-dependent secretion of BDNF (Egan et al., 2003). Stress has been found to compound the effects that the BDNF Met-allele has on BDNF levels, resulting in increased anxiety and depression (Gatt et al., 2009; Elzinga et al., 2011). Indeed, Met-allele carriers have been found to be more sensitive to childhood abuse than Val-carriers, which could result in later psychopathology. This may be due to reduced neural plasticity caused by the altered release of BDNF during development (Gatt et al., 2009). Although childhood emotional abuse was found to increase the severity of OCD, no interactive effect between childhood trauma and BDNF Val66Met on severity of OCD was observed in the present study, indicating that other factors, environmental and/or genetic, may be acting in concert with childhood trauma to increase severity of the disorder.

The findings in the present study underscore the importance of considering $\mathrm{G} \times \mathrm{E}$ interactions in OCD association studies, and may, at least partially, explain some of the inconsistencies observed in previous studies investigating the role that $B D N F$ may play in the development of OCD. Previous studies have implicated both the BDNF Val- (Hall et al., 2003) and Met-alleles in the development of OCD (Hemmings et al., 2008; Katerberg et al., 2009). Our group has previously found that the $M e t$-allele represented a risk allele for the development of OCD in males, while females homozygous for the Val-allele exhibited more severe OCD symptoms (Hemmings et al., 2008; Katerberg et al., 2009). 


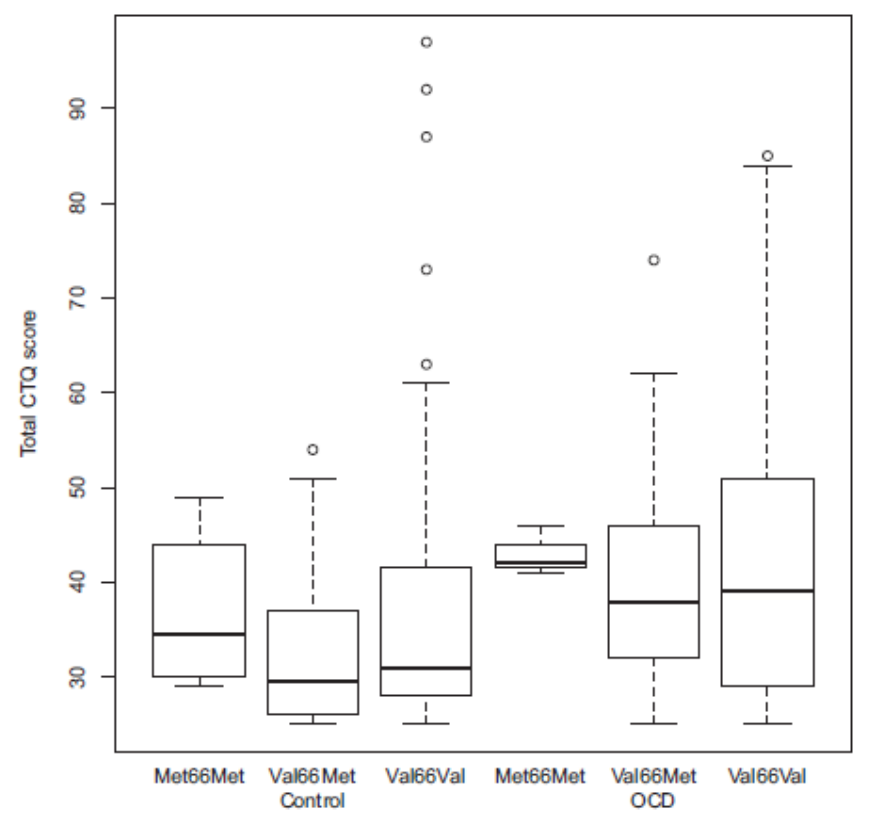

Fig. 1. Box plot indicating the distribution of total CTQ scores per BDNF Val66Met genotype, in $O C D$ cases and controls.

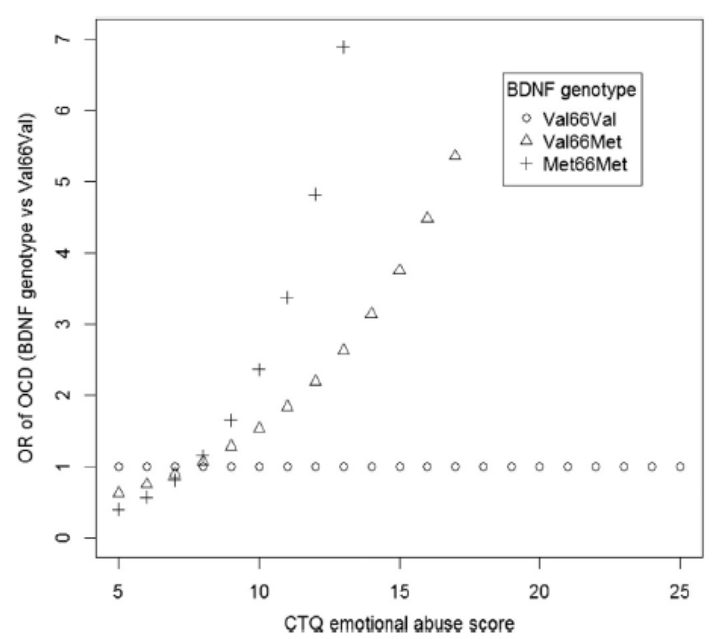

Fig 2. The symbols represent the predicted $O R$ of $O C D$ according to each $B D N F$ Val66Met genotype (Val66Val, Val66Met and Met66Met) at each value of emotional abuse on the CTQ scale, relative to the reference genotype, Val66Val $(O R=1)$. Predictions are valid for comparing individuals of the same age, gender, language and minimisation/denial score.

In the present study, we found that the Met-allele is particularly associated with OCD in the presence of early adversity; thus it could be argued that it is not that BDNF has different associations based on gender, but rather that the inconsistent results are due to variation in early adversity.

Due to the high degree of comorbid MDD in the OCD group, we investigated the probability that childhood trauma was linked to the development of comorbid MDD, and was not unique to the development of OCD. No significant differences in CTQ scores between OCD individuals with comorbid MDD and those without were noted, making it difficult to decipher whether childhood trauma was significantly 
associated with the development of OCD or the co-occurrence of the two disorders. This represents a limitation of the present study, and should be rectified in future studies comprising larger study groups.

Other limitations in the present study deserve mention. First, the present study included only one type of environmental risk factor (childhood adversity) in the analyses. There are, however, numerous environmental factors that have been identified as increasing the risk for OCD that could be included in future investigations. In addition, more recent life events may perhaps have had more influence on the development of OCD than more distal events, as has been found in depression (Middeldorp et al., 2010). One should also account for the possibility that negative outcomes often associated with childhood adversity may be modified by subsequent environmental factors, such as available positive social support and optimal caregiving experiences (Barbazanges et al., 1996; Kaufman et al., 2000; Huot et al., 2004). Positive environmental factors that could ameliorate the development of psychopathology should thus be incorporated into future G $\mathrm{x}$ E studies.

Second, the CTQ, although a reliable and validated means of trauma assessment (Bernstein and Fink, 1998), may be vulnerable to a number of biases, including recall bias, by virtue of its self-assessment, retrospective qualities. Third, a crucial assumption in all $\mathrm{G} \times \mathrm{E}$ studies is that genetics and environmental factors are independent, because the presence of geneeenvironment correlation (rGEs) confound the identification and subsequent interpretation of $\mathrm{G} \times \mathrm{E}$ interactions (Moffitt et al., 2005; Jaffee and Price, 2007). Geneeenvironment correlation was not corrected for in the present study; thus the significant interaction effects should be regarded as preliminary and requiring replication.

Finally, it is important to note that controls used in the present study were from a cohort of "convenience controls" i.e. they were randomly selected Caucasian blood donors who, although they were given a brief psychiatric screening test, did not undergo a structured interview. We can therefore not rule out the possibility that this screening procedure may have overlooked individuals with sub-threshold or mild OCD.

Despite the limitations, the present study sheds light on the $\mathrm{G} \times \mathrm{E}$ interaction in the development of OCD, and as such, implicates interaction between BDNF Val66Met and childhood adversity in the development of the disorder. Studies incorporating interactions between genes and the environment may improve our understanding of inconsistent results that are obtained frequently in genetic association studies, and may improve replicability of future studies. 


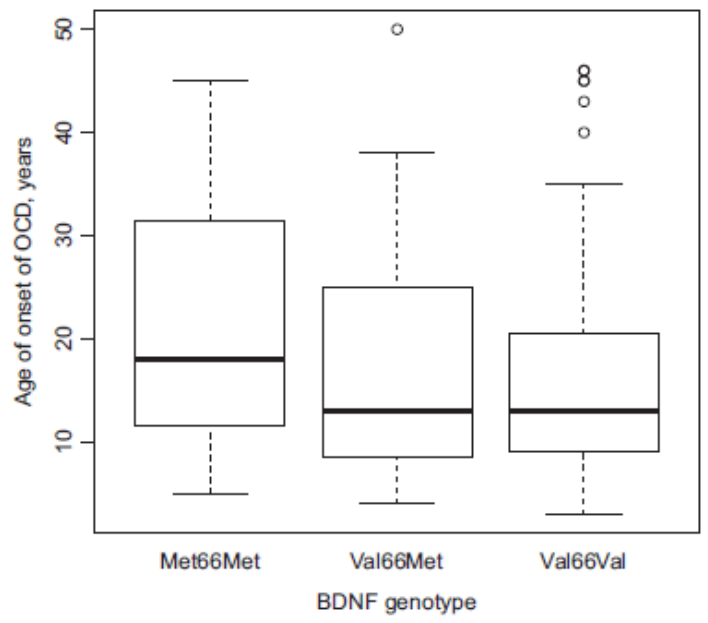

Fig. 3. Box plot indicating the distribution of age at onset of OCD per BDNF Val66Met genotype.

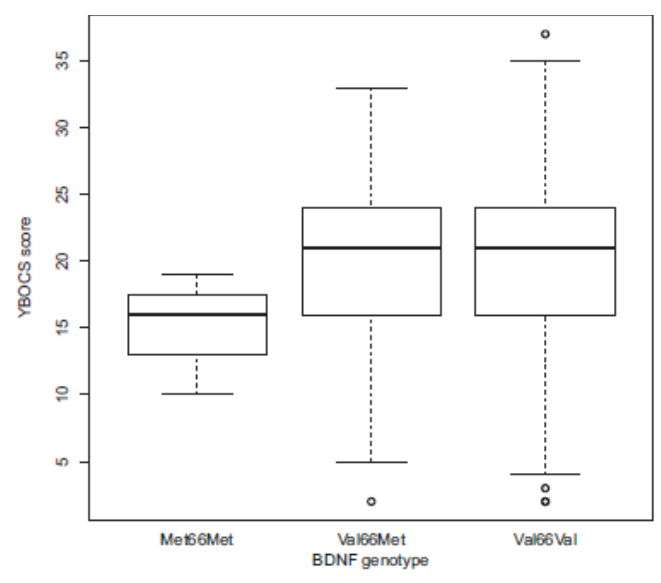

Fig. 4. Box plot indicating the distribution of YBOCS score per BDNF Val66Me genotype.

\section{Conflict of interest}

No conflict declared.

\section{Role of funding sources}

This work is based upon research supported by the Harry Crossley Foundation and the Medical Research Council of South Africa. These funding bodies had no further role in the study design or analysis.

\section{Contributors}

Authors SMJH and DJS conceived of the idea, author SMJH led the analysis and wrote the first draft of the manuscript; author CL recruited and interviewed patients and controls; author LvdM performed the statistical analyses and wrote parts of the manuscript; authors CL, DC, SS and DJS provided intellectual input and reviewed various drafts of the manuscript. All authors contributed to and have approved the final manuscript. 


\section{Acknowledgements}

The authors thank Melissa du Plessis for assistance with genotyping; we also wish to thank the MRC Centre for Molecular and Cellular Biology, Division of Molecular Biology and Human Genetics, Faculty of Medicine and Health Sciences, Stellenbosch University, Cape Town, South Africa.

Statistical support was provided by the Biostatistics Unit, South African Medical Research Council. 


\section{References}

Aguilera M, Arias B, Wichers M, Barrantes-Vidal N, Moya J, Villa H, et al. Early adversity and 5-HTT/BDNF genes: new evidence of geneeenvironment interactions on depressive symptoms in a general population. Psychological Medicine 2009;39:1425e32.

Alonso P, Gratacos M, Menchon JM, Saiz-Ruiz J, Segalas C, Baca-Garcia E, et al. Extensive genotyping of the BDNF and NTRK2 genes define protective haplotypes against obsessive-compulsive disorder. Biological Psychiatry 2008;63: 619e28.

Angst J, Gamma A, Endrass J, Goodwin R, Ajdacic V, Eich D, et al. Obsessivecompulsive severity spectrum in the community: prevalence, comorbidity, and course. European Archives of Psychiatry and Clinical Neuroscience 2004;254(3):156e64.

Astle W, Balding D. Population structure and cryptic relatedness in genetic asso ciation studies. Statistical Science 2009;24(4):451e71.

Barbazanges A, Vallee M, Mayo W, Day J, Simon H, Le Moal M, et al. Early and later adoptions have different long-term effects on male rat offspring. Journal of Neuroscience 1996;16:7783e90.

Bernstein DP, Fink L. Manual for the childhood trauma questionnaire: a retrospective self-report. The Psychological Corporation. New York: Harcourt Brace; 1998.

Black DW, Noyes Jr R, Goldstein RB, Blum N. A family study of obsessivecompulsive disorder. Archives of General Psychiatry 1992;49:362e8.

Briggs ES, Price IR. The relationship between adverse childhood experience and obsessive-compulsive symptoms and beliefs: the role of anxiety, depression, and experiential avoidance. Journal of Anxiety Disorders 2009;23:1037e46.

Carver CS, Johnson SL, Joormann J, Lemoult J, Cuccaro ML. Childhood adversity interacts separately with 5-HTTLPR and BDNF to predict lifetime depression diagnosis. Journal of Affective Disorders 2011;132:89e93.

Casey BJ, Glatt CE, Tottenham N, Soliman F, Bath K, Amso D, et al. Brain-derived neurotrophic factor as a model system for examining gene by environment interactions across development. Neuroscience 2009;164:108e20.

Dickel DE, Veenstra-Vanderweele J, Bivens NC, Wu X, Fischer DJ, Van Etten-Lee $\mathrm{M}$, et al. Association studies of serotonin system candidate genes in earlyonset obsessive-compulsive disorder. Biological Psychiatry 2007;61:322e9.

Do Rosario-Campos MC, Leckman JF, Curi M, Quatrano S, Katsovitch L, Miguel EC, et al. A family study of early-onset obsessive-compulsive disorder. American Journal of Medical Genetics Part B, Neuropsychiatric Genetics 2005;136B:92e7. Duman RS, Monteggia LM. A neurotrophic model for stress-related mood disorders. Biological Psychiatry 2006;59:1116e27.

Du Toit PL, van Kradenburg J, Niehaus D, Stein DJ. Comparison of obsessivecompulsive disorder patients with and without comorbid putative 
obsessive-compulsive spectrum disorders using a structured clinical interview. Comprehensive Psychiatry 2001;42:291e300.

Egan MF, Kojima M, Callicott JH, Goldberg TE, Kolachana BS, Bertolino A, et al. The BDNF val66met polymorphism affects activity-dependent secretion of BDNF and human memory and hippocampal function. Cell 2003;112:257e69.

Elzinga BM, Molendijk ML, Oude Voshaar RC, Bus BA, Prickaerts J, Spinhoven P, et al. The impact of childhood abuse and recent stress on serum brain-derived neurotrophic factor and the moderating role of BDNF Val66Met. Psychopharmacology (Berl) 2011;214:319e28.

First MB, Spitzer RL, Gobbon M, Williams JBW. Structured clinical interview for DSM-IV axis I disorders e patient edition (SCID-I/P, version 2.0, 8/98 revision). New York: New York State Psychiatric Institute, Biometrics Department; 1998.

Gatt JM, Nemeroff CB, Dobson-Stone C, Paul RH, Bryant RA, Schofield PR, et al. Interactions between BDNF Val66Met polymorphism and early life stress predict brain and arousal pathways to syndromal depression and anxiety. Molecular Psychiatry 2009;14:681e95.

Goodman WK, Price LH, Rasmussen SA, Mazure C, Fleischmann RL, Hill CL, et al. The Yale-Brown obsessive compulsive scale. I. Development, use, and reliability. Archives of General Psychiatry 1989;46:1006e11.

Gothelf D, Aharonovsky O, Horesh N, Carty T, Apter A. Life events and personality factors in children and adolescents with obsessive-compulsive disorder and other anxiety disorders. Comprehensive Psychiatry 2004;45(3):192e8.

Hall D, Dhilla A, Charalambous A, Gogos JA, Karayiorgou M. Sequence variants of the brain-derived neurotrophic factor (BDNF) gene are strongly associated with obsessive-compulsive disorder. American Journal of Human Genetics 2003;73(2):370e6.

Hanna GL, Fingerlin TE, Himle JA, Boehnke M. Complex segregation analysis of obsessive-compulsive disorder in families with pediatric probands. Human Heredity 2005;60:1e9.

Hemmings SM, Kinnear CJ, van der Merwe L, Lochner C, Corfield VA, MoolmanSmook JC, et al. Investigating the role of the brain-derived neurotrophic factor (BDNF) val66met variant in obsessive-compulsive disorder (OCD). World Journal of Biological Psychiatry 2008;9:126e34.

Hoglinger GU, Sautter J, Meyer M, Spenger C, Seiler RW, Oertel WH, et al. Rat fetal ventral mesencephalon grown as solid tissue cultures: influence of culture time and BDNF treatment on dopamine neuron survival and function. Brain Research 1998;813:313e22.

Huang EJ, Reichardt LF. Neurotrophins: roles in neuronal development and function. Annual Review of Neuroscience 2001;24:677e736.

Huot RL, Gonzalez ME, Ladd CO, Thrivikraman KV, Plotsky PM. Foster litters prevent hypothalamicepituitaryeadrenal axis sensitization mediated by 
Jaffee SR, Price TS. Geneeenvironment correlations: a review of the evidence and implications for prevention of mental illness. Molecular Psychiatry 2007;12(5): $432 \mathrm{e} 42$.

Katerberg H, Lochner C, Cath DC, de JP, Bochdanovits Z, Moolman-Smook JC, et al. The role of the brain-derived neurotrophic factor (BDNF) val66met variant in the phenotypic expression of obsessive-compulsive disorder (OCD). American Journal of Medical Genetics. Part B, Neuropsychiatric Genetics 2009;150B(8): 1050 62.

Kaufman J, Plotsky PM, Nemeroff CB, Charney DS. Effects of early adverse experiences on brain structure and function: clinical implications. Biological Psychi atry 2000;48:778e90.

Lochner C, Du Toit PL, Zungu-Dirwayi N, Marais A, Van Kradenburg J, Seedat S, et al. Childhood trauma in obsessive-compulsive disorder, trichotillomania and controls. Depression and Anxiety 2002;68:66e8.

Lu B. BDNF and activity-dependent synaptic modulation. Learning \& Memory 2003;10:86e98.

Mathews CA, Kaur N, Stein MB. Childhood trauma and obsessive-compulsive symptoms. Depression and Anxiety 2008;25(9):742e51.

McKeon J, Roa B, Mann A. Life events and personality traits in obsessivecompulsive neurosis. British Journal of Psychiatry 1984;144:185e9.

Middeldorp CM, De Geus EJ, Willemsen G, Hottenga JJ, Slagboom PE, Boomsma DI. The serotonin transporter gene length polymorphism (5HTTLPR) and life events: no evidence for an interaction effect on neuroticism and anxious depressive symptoms. Twin Research and Human Genetics 2010;13:544e9.

Moffitt TE, Caspi A, Rutter M. Strategy for investigating interactions between measured genes and measured environments. Archives of General Psychiatry 2005;62:473e81.

Mossner R, Walitza S, Lesch KP, Geller F, Barth N, Remschmidt H, et al. Brainderived neurotrophic factor V66M polymorphism in childhood-onset obsessive-compulsive disorder. International Journal of Neuropsychopharmacology 2005;8:133e6.

Nicolini H, Arnold P, Nestadt G, Lanzagorta N, Kennedy JL. Overview of genetics and obsessive-compulsive disorder. Psychiatry Research 2009;170(1):7e14.

Pauls DL. The genetics of obsessive-compulsive disorder: a review. Dialogues in Clinical Neuroscience 2010;12:149e63.

Perroud N, Courtet P, Vincze I, Jaussent I, Jollant F, Bellivier F, et al. Interaction between BDNF Val66Met and childhood trauma on adult's violent suicide attempt. Genes, Brain, and Behavior 2008;7(3):314e22.

Pregelj P, Nedic G, Paska AV, Zupanc T, Nikolac M, Balazic J, et al. The association between brain-derived neurotrophic factor polymorphism (BDNF Val66Met) and suicide. Journal of Affective Disorders 2011;128(3):287-90. 
Ruscio AM, Stein DJ, Chiu WT, Kessler RC. The epidemiology of obsessivecompulsive disorder in the national comorbidity survey replication. Molecular Psychiatry 2010;15:53-63.

Samuels JF. Recent advances in the genetics of obsessive-compulsive disorder. Current Psychiatry Reports 2009;11:277-82.

Stein DJ, Daniels WM, Savitz J, Harvey BH. Brain-derived neurotrophic factor: the neurotrophin hypothesis of psychopathology. CNS Spectrums 2008;13:945- 9 .

Tukel R, Gurvit H, Ozata B, Ozturk N, Ertekin BA, Ertekin E, et al. Brain-derived neurotrophic factor gene Val66Met polymorphism and cognitive function in obsessive-compulsive disorder. American Journal of Medical Genetics Part B, Neuropsychiatric Genetics 2012;159B:850-8.

van Grootheest DS, Cath DC, Beekman AT, Boomsma DI. Twin studies on obsessivecompulsive disorder: a review. Twin Research and Human Genetics 2005;8: 450- 8 .

Warnes G, Gorjanc G, Leisch F, Man M. Genetics: population genetics. R package version 1.3.6. Available from: http://cran.r-project.org/package/genetics; 2011.

Wendland JR, Kruse MR, Cromer KR, Murphy DL. A large caseecontrol study of common functional SLC6A4 and BDNF variants in obsessive-compulsive disorder. Neuropsychopharmacology 2007 Dec;32:2543e51. 